\title{
Genome-Wide Linkage Analysis of Families With Obsessive-Compulsive Disorder Ascertained Through Pediatric Probands
}

\author{
Gregory L. Hanna, ${ }^{1 *}$ Jeremy Veenstra-VanderWeele, ${ }^{2}$ Nancy ${ }^{*}$. Cox,${ }^{3}$ Michael Boehnke, ${ }^{4}$ \\ Joseph A. Himle, ${ }^{1}$ George C. Curtis, ${ }^{1}$ Bennett L. Leventhal, ${ }^{2}$ and Edwin H. Cook, Jr ${ }^{2}$ \\ ${ }^{1}$ Department of Psychiatry, University of Michigan, Ann Arbor, Michigan \\ ${ }^{2}$ Departments of Psychiatry and Pediatrics, University of Chicago, Chicago, Illinois \\ ${ }^{3}$ Department of Human Genetics, University of Chicago, Chicago, Illinois \\ ${ }^{4}$ Department of Biostatistics, University of Michigan, Ann Arbor, Michigan
}

The goal of this study was to identify chromosomal regions likely to contain susceptibility alleles for early-onset obsessivecompulsive disorder (OCD). A genome scan was done in 56 individuals from seven families ascertained through pediatric OCD probands; 27 of the 56 subjects had a lifetime diagnosis of definite OCD. Denser mapping of regions on chromosomes 2,9 , and 16 was subsequently done with those subjects and ten additional subjects from the largest family in the study. Direct interviews were completed with 65 of the 66 genotyped individuals. Relatives were interviewed blind to proband status. Of the 65 interviewed individuals, 32 had a lifetime diagnosis of definite OCD. Three of the seven probands had a history of Tourette disorder. Two of the 25 relatives with OCD had a tic history, whereas none of the 33 relatives without OCD had tics. The genome scan consisted of 349 microsatellite markers with an average between-marker distance of 11.3 centiMorgan (cM). Fine mapping was done with 24 additional markers at an average spacing of $1.6 \mathrm{cM}$. Parametric and nonparametric

Grant sponsor: National Institutes of Health; Grant numbers: K20 MH-01065, K02 MH-01389, R01 MH58376; Grant sponsor: Obsessive Compulsive Foundation; Grant sponsor: Brain Research Foundation, University of Chicago; Grant sponsor: Jean Young and Walden W. Shaw Foundation; Grant sponsor: Harris Foundation.

*Correspondence to: Gregory L. Hanna, M.D., Department of Psychiatry, University of Michigan, 1500 East Medical Center Drive, Ann Arbor, MI 48109-0390. E-mail: ghanna@umich.edu Received 20 December 2001; Accepted 13 March 2002 DOI 10.1002/ajmg.10519 linkage analyses were conducted using GENEHUNTER $^{+}$. The maximum multipoint LOD score with a dominant model was 2.25 on 9p. However, with fine mapping and additional subjects, that LOD score decreased to 1.97. The maximum multipoint nonparametric LOD* score was 1.73 on 19q. The maximum multipoint LOD score with a recessive model was 1.40 on $6 \mathrm{p}$. The results provide suggestive evidence for linkage on $9 p$ and identify regions requiring further study with much larger samples.

๑) 2002 Wiley-Liss, Inc.

KEY WORDS: obsessive-compulsive disorder; Tourette disorder; linkage analysis; genome scan; microsatellite markers; susceptibility loci

DATABASE: OCD

\section{INTRODUCTION}

Obsessive-compulsive disorder (OCD [MIM 164230]) is characterized by recurrent, intrusive thoughts that cause marked distress, and by repetitive behaviors or mental acts that are aimed at reducing distress or preventing a dreaded event. In contrast to other forms of severe psychopathology, the symptoms of OCD are virtually identical in children and adults [Hanna, 1995; Geller et al., 1998]. Estimates of the lifetime prevalence of OCD in adolescent and adult samples have ranged from $1 \%$ to $3 \%$ in the United States [Flament et al., 1988; Karno et al., 1988; Reinherz et al., 1993; ValleniBasile et al., 1994] and eight other countries [Zohar et al., 1992; Thomsen, 1993; Weissman et al., 1994; Douglass et al., 1995]. Clinical and community studies of adults with OCD have established an average age at onset in early adulthood, with males having earlier onset than females [Burke et al., 1990; Noshirvani et al., 1991]. 
There is substantial evidence for a genetic contribution to the etiology of OCD [Hettema et al., 2001]. In two of the larger twin studies, the concordance rates ranged from 80 to $87 \%$ for monozygotic twins and from 47 to $50 \%$ for dizygotic twins, depending on the sample and diagnostic criteria [Inouye, 1965; Carey and Gottesman, 1981]. Multivariate analyses have provided a heritability estimate of $47 \%$ for obsessional symptoms [Clifford et al., 1984]. Recent controlled family studies using adult probands have found that the lifetime prevalence of OCD is significantly higher in case compared with control relatives, and that an early age at onset of obsessive-compulsive symptoms in case probands is strongly related to a more familial form of the disorder [Pauls et al., 1995; Nestadt et al., 2000a].

Family studies using child and adolescent probands have also consistently indicated that OCD is familial [Last and Strauss, 1989; Lenane et al., 1990; Leonard et al., 1992]. The rate of OCD in the first-degree relatives of the probands in those studies has ranged from 7.7 to $17 \%$. In one of the larger studies, the agecorrected rate of OCD and subclinical OCD in the firstdegree relatives was 35\% [Lenane et al., 1990]. Early age at onset has previously been associated with increased familial risk in several psychiatric disorders, including major depression [Weissman et al., 1988], bipolar disorder [Pauls et al., 1992], schizophrenia [Pulver et al., 1990], and panic disorder [Goldstein et al., 1997].

Segregation analyses have provided evidence for a single major locus in OCD without establishing a mode of inheritance [Nicolini et al., 1991; Alsobrook et al., 1999; Cavallini et al., 1999; Nestadt et al., 2000b]. The most recent complex segregation analysis found that the dominant model of transmission best explained their results and that the recessive model of transmission could be excluded [Nestadt et al., 2000b]. However, Mendelian factors only partially explained the familial aggregation of the phenotype, and residual familial effects were necessary to adequately fit the data. That suggested polygenic factors may also contribute to the etiology of OCD.

Although some forms of OCD appear familial, the genetics of the disorder is complex. By ascertaining probands with an early onset of the disorder, families may be identified for genetic linkage studies with extensive aggregation of the disorder and possibly less etiologic heterogeneity [Lander and Schork, 1994]. That strategy has been used successfully in molecular genetic studies of other complex diseases, including breast cancer [Hall et al., 1990] and Alzheimer disease [Van Broeckhoven et al., 1992].

We initially conducted a preliminary genome scan for DNA markers cosegregating with susceptibility loci for early-onset OCD, using 349 microsatellite markers in 56 individuals from seven families ascertained through child and adolescent OCD probands. The pedigree structures were consistent with segregation analyses of OCD indicating a gene of large effect [Nicolini et al., 1991; Alsobrook et al., 1999; Cavallini et al., 1999; Nestadt et al., 2000b]. We report a locus on chromosome 9 with suggestive evidence for linkage under a dominant model of inheritance, and several loci with weaker evidence for linkage using parametric and nonparametric analyses. Denser mapping of regions on chromosomes 2,9 , and 16 was subsequently performed in an extended sample.

\section{MATERIALS AND METHODS}

\section{Subject Ascertainment and Diagnosis}

The probands in the genome scan were five boys and two girls with a current diagnosis of definite OCD. They ranged in age from six to 17 years $(14.4 \pm 3.8$ years, mean $\pm \mathrm{SD}$ ). OCD onset age in the probands ranged from three to 14 years $(8.8 \pm 3.9$ years, mean $\pm \mathrm{SD})$. Three probands also had a history of Tourette disorder. No probands had a history of obsessive-compulsive symptoms or tics related to streptococcal infection [Swedo et al., 1998]. The probands were recruited from clinics at the University of Michigan Medical Center and local chapters of the Obsessive-Compulsive Foundation as part of a family study of pediatric OCD.

All probands were directly interviewed to determine whether they met DSM-III-R criteria for OCD [American Psychiatric Association, 1987]. Exclusion criteria for the probands were: 1) chronic neurological disorder (other than tic disorder); 2) mental retardation; 3) DSM-III-R diagnosis of autistic disorder, schizophrenia, or bipolar disorder; 4) currently living away from both biological parents; and 5) adoption. Written informed consent was obtained from both parents and informed assent from each proband. The study was approved by the Institutional Review Board of the University of Michigan Medical Center.

After completing the proband diagnostic evaluation, permission to contact other relatives was requested from the parents. Direct interviews were done with all 26 first-degree relatives. Direct interviews were done with 20 of $22(91 \%)$ second-degree relatives contacted for further diagnostic evaluation; however, a blood sample was not obtained from one interviewed seconddegree relative. Direct interviews were done with 13 more distant relatives in two families. A blood sample was obtained only for fine mapping from one distant relative in the largest family (see Fig. 1) without completing a diagnostic evaluation.

After informed consent and assent were obtained, probands and siblings between 10 and 17 years of age were interviewed with the Schedule for Affective Disorders and Schizophrenia for School Age ChildrenEpidemiologic Version (K-SADS-E) [Orvaschel, 1987]. Siblings and other relatives less than 10 years were not included in the study. The interview was completed independently with a parent of the subject, as well as with the subject. It was supplemented with sections on OCD and tic disorders from the Schedule for Tourette and Other Behavioral Syndromes (Version C1) [Pauls and Hurst, 1991a; Pauls et al., 1995]. Relatives 18 years and older were interviewed with the Structured Clinical Interview for DSM-III-R (SCID) [Spitzer et al., 1990, 1992; Williams et al., 1992] and sections on OCD and tic disorders from the Schedule for 


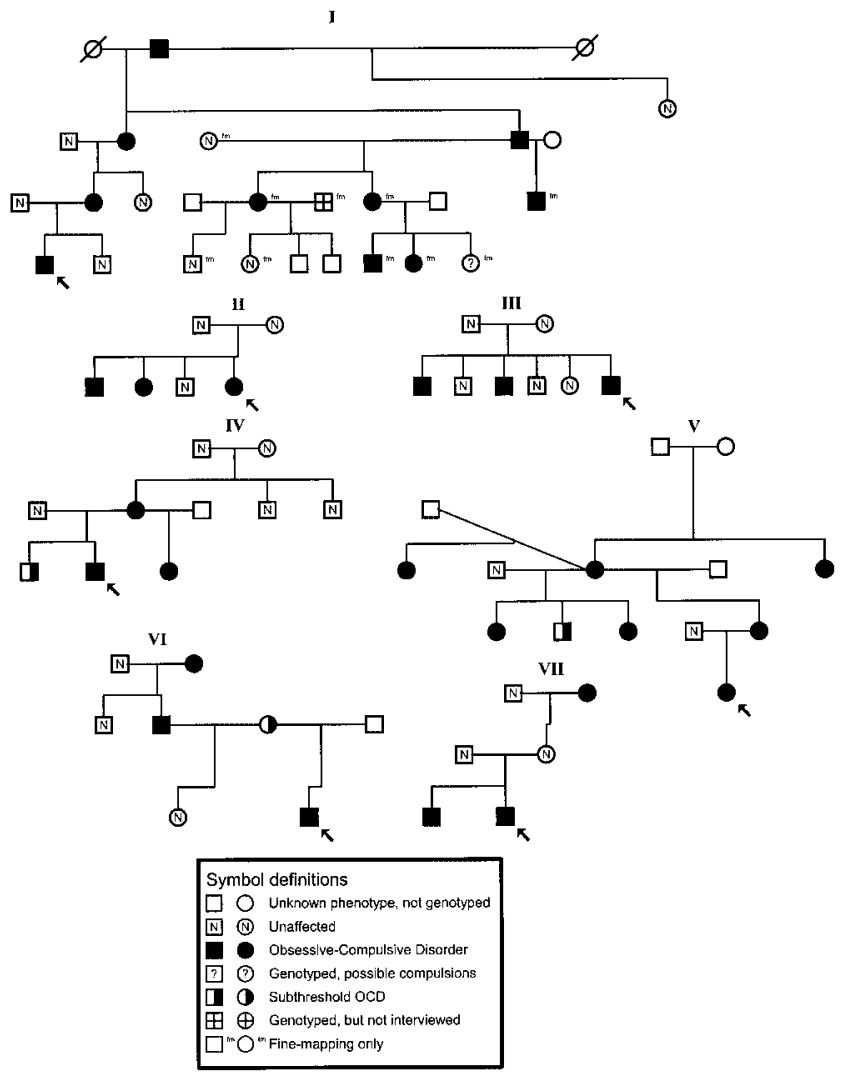

Fig. 1. The structures of the seven pedigrees used in a genome scan of early-onset OCD are presented with symbol definitions.

Tourette and Other Behavioral Disorders (Version A1) [Pauls and Hurst, 1991b]. The section on OCD included a series of screening questions designed to cover all criteria for a DSM-III-R diagnosis of OCD [Pauls et al., 1995] and a checklist from the Yale-Brown Obsessive Compulsive Scale (Y-BOCS) [Goodman et al., 1989a, $1989 \mathrm{~b}$ ] modified to obtain information about the lifetime occurrence of obsessions and compulsions.

Additional information on relatives 18 years and older was obtained with the Family Informant Schedule and Criteria (FISC) [Mannuzza et al., 1985]. The mother of each affected offspring was interviewed with the FISC regarding her spouse, adult offspring, parents, and siblings. The father of each affected offspring was interviewed with the FISC regarding his spouse, parents, and siblings. The maternal grandmother provided FISC information for the third-degree relatives in the largest pedigree (see Fig. 1). Thus, two types of data were obtained on all adult subjects: 1) information from direct structured interviews and 2) personal history information from a biological relative and/or spouse.

All interviews were audiotaped, as well as coded on paper. All interviewers had at least a masters degree and clinical training in either child or adult psychopathology. They were trained to at least $90 \%$ diagnostic agreement with the individual instruments. The interviewers were confined to interviewing either probands and their relatives between 10 and 17 years of age, or adult relatives. The interviewer for a given proband was not involved with the interviews of other family members. Because control probands and their relatives were included in an ongoing family study, the interviewers were blind to proband status.

After completion of all interviews for an individual, all available materials (personal interview data, family history data, and clinical records) were collated. All information identifying or describing the proband was removed so that diagnostic ratings could be completed by raters blind to proband diagnosis. The blinded diagnosticians were never given a complete family to evaluate at one time, and all diagnostic evaluations of probands were done separately from those of the relatives.

Best-estimate lifetime diagnoses were made independently by two investigators using DSM-III-R criteria. Definite OCD was diagnosed only if a subject met all diagnostic criteria. Subthreshold OCD was diagnosed if a subject met criteria for obsessions and/or compulsions, but lacked compelling evidence for any of the following criteria: 1) marked distress; 2) duration of obsessive-compulsive symptoms for more than one hour per day; or 3) significant interference in the person's normal routine, occupational (or academic) functioning, or usual social activities or relationships with others. When major disagreements occurred between two diagnosticians, consensus diagnoses were reached with the assistance of a third diagnostician following established procedures developed for the diagnosis of other psychiatric disorders [Leckman et al., 1982; Klein et al., 1994].

Only individuals with a lifetime diagnosis of definite OCD were considered affected. Relatives with either a lifetime diagnosis of subthreshold OCD or a history of probable obsessions or compulsions were considered unknown. Other aspects of the interviewing and diagnostic process have previously been described in detail [Hanna et al., 1998; Veenstra-VanderWeele et al., 2001].

\section{Genotyping}

Peripheral blood samples were obtained by venipuncture from 66 consenting individuals. Samples were immediately transported to the laboratory and stored frozen at $-70^{\circ} \mathrm{C}$ until the time of DNA extraction. DNA was extracted using the PureGene DNA Isolation Kit (Gentra Systems, Minneapolis, MN).

Fifty-six individuals from seven families were initially genotyped with 349 microsatellite markers from the 28 panels of the ABI PRISM Linkage Mapping Set version 1 (LMS v. 1), with an average between-marker distance of 11.3 centiMorgan (cM) and an average heterozygosity of 0.81 . Twenty-four additional markers were subsequently typed for fine mapping of three chromosomal regions at an average spacing of $1.6 \mathrm{cM}$ for a total of 373 markers in the original 56 subjects. Ten additional subjects from family 1 were also typed for the 24 fine mapping markers along with seven flanking LMS v. 1 markers. However, those 10 subjects were not genotyped for the rest of the LMS v. 1. 
Primer sequences for these markers are available at The Genome Database with one exception, EAAC1, which has been described separately [VeenstraVanderWeele et al., 2001]. Table I shows these markers with genetic positions calculated from available genetic and physical map data. When the genetic map distance between two markers was estimated as 0 and physical map distance was not available or less than $10 \mathrm{~kb}$, a cM distance of 0.01 was assigned. When genetic map data were not available, physical map data were used to place the marker between other markers that had both genetic and physical map data.

In preparation for efficient genotyping, multiplex polymerase chain reaction (PCR) for each panel was optimized with the goal of one multiplex PCR for each of the three fluorescent labeling colors in each panel. Therefore, only 117 PCRs were required to amplify 349 microsatellites. This process also led to optimal peak heights for each marker. Amplification of the LMS v. 1 was carried out as under multiplex and singleplex conditions described previously [Veenstra-VanderWeele et al., 1998] and available at http://www.genes.uchicago.edu/panels/psy.html. The fine mapping markers were amplified by singleplex PCR under the same conditions (see Table I). The average genotyping failure rate was $8 \%$. The average genotype-wise Mendelian incompatibility rate was $0.8 \%$ across the genome.

PCR products for each panel were pooled using ratios adjusted to give even peak heights across fluorescent labeling colors. Pooled PCR products were separated by

TABLE I. Fine Mapping Markers

\begin{tabular}{|c|c|c|}
\hline Chromosome & Marker & $\mathrm{cM}$ \\
\hline 2 & D2S396 & 237.10 \\
\hline 2 & D2S172 & 239.20 \\
\hline 2 & D2S2340 & 239.21 \\
\hline 2 & GATA67B01 & 240.71 \\
\hline 2 & GATA12H10 & 240.81 \\
\hline 2 & D2S206 & 244.91 \\
\hline 9 & D9S1779 & 0.00 \\
\hline 9 & D9S1858 & 0.10 \\
\hline 9 & D9S129 & 2.90 \\
\hline 9 & D9S54 & 7.00 \\
\hline 9 & D9S288 & 9.90 \\
\hline 9 & D9S178 & 10.10 \\
\hline 9 & D9S1813 & 10.11 \\
\hline 9 & D9S1792 & 10.31 \\
\hline 9 & GATA62F03 & 14.71 \\
\hline 9 & EAAC1 & 15.31 \\
\hline 9 & D9S199 & 15.32 \\
\hline 9 & D9S1852 & 15.42 \\
\hline 9 & D9S281 & 16.02 \\
\hline 9 & D9S286 & 18.72 \\
\hline 16 & D16S515 & 79.80 \\
\hline 16 & D16S3097 & 81.50 \\
\hline 16 & D16S3142 & 81.51 \\
\hline 16 & D16S3049 & 84.81 \\
\hline 16 & D16S516 & 88.21 \\
\hline 16 & D16S3104 & 93.01 \\
\hline 16 & D16S3119 & 93.02 \\
\hline 16 & D16S3073 & 93.03 \\
\hline 16 & D16S507 & 93.04 \\
\hline 16 & D16S505 & 96.84 \\
\hline 16 & D16S511 & 98.24 \\
\hline
\end{tabular}

capillary electrophoresis on an ABI Prism 310 Genetic Analyzer. Fluorescent peaks were analyzed using ABI GeneScan Analysis version 2.02 and the local Southern sizing method. Genotypes were assigned blind to pedigree structure and clinical data using ABI Genotyper version 2.0 .

\section{Genetic Linkage Analysis}

Parametric and nonparametric linkage analyses were conducted with GENEHUNTER [Kruglyak et al., 1996] and a modification of that program, GENEHUNTER $^{+}$[Kong and Cox, 1997]. GENEHUNTER extracts complete multipoint inheritance information from pedigrees of moderate size with diverse structures. Because of memory constraints, the extension of family 1 used in fine mapping was analyzed as a separate sub-family. GENEHUNTER provides exact computation of multipoint LOD scores (decimal logarithms of the likelihood ratio under the hypotheses of linkage and no linkage) involving dozens of highly polymorphic markers and a nonparametric linkage (NPL) analysis that is robust to uncertainty about mode of inheritance.

GENEHUNTER was configured to calculate the more conservative nonparametric pairs statistic $\left(\mathrm{NPL}_{\text {pairs }}\right)$. Examining all individuals simultaneously would yield more power, but is also more likely to produce false positive findings in a small sample [Kong and Cox, 1997]. In the parametric analysis, we assumed reduced, age-dependent penetrance and sporadic cases, with both penetrance and sporadic case rate increasing with age, and the proportion of sporadic cases among all cases increasing with age. The result is that the disease status of young unaffected individuals and affected individuals with late age at onset provides less information on the putative disease locus than early onset affected individuals, but that all individuals still provide full information on the genetic marker(s). Age at onset was specified as a linear function from two to 25 years. The lifetime prevalence of the affected phenotype was estimated to be $2.5 \%$. Sex ratio was assumed to be 1:1 [American Psychiatric Association, 1994].

Two simple genetic models were used in the parametric analyses: a dominant model in which $1>$ $\mathrm{f}(\mathrm{DD} ; \mathrm{a})=\mathrm{f}(\mathrm{Dd} ; \mathrm{a})>\mathrm{f}(\mathrm{dd}: \mathrm{a})>0$ and a recessive model in which $1>f(D D ; a)>f(D d: a)=f(d d ; a)>0$. Recent evidence suggests that a critical factor in LOD score analysis is the mode of inheritance at the linked locus, not that of the disease or trait in itself [Greenberg et al., 1998]. Because other genes and environmental factors are almost certainly involved in the etiology of OCD, we chose penetrances for non-disease-susceptibility genotypes to be greater than zero and the gene frequency to

TABLE II. Parameters Used for Parametric Linkage Analysis

\begin{tabular}{|c|c|c|c|c|c|}
\hline \multirow{2}{*}{$\begin{array}{l}\text { Genetic } \\
\text { model }\end{array}$} & \multicolumn{3}{|c|}{ Maximum penetrance } & \multirow{2}{*}{$\begin{array}{l}\text { Phenocopy } \\
\text { proportion }\end{array}$} & \multirow{2}{*}{$\begin{array}{c}\text { Disease } \\
\text { allele } \\
\text { frequency }\end{array}$} \\
\hline & $\mathrm{AA}$ & $\mathrm{Aa}$ & aa & & \\
\hline Dominant & 0.50 & 0.50 & 0.0052 & 0.20 & 0.02 \\
\hline Recessive & 0.50 & 0.0052 & 0.0052 & 0.20 & 0.20 \\
\hline
\end{tabular}


be relatively large (see Table II). These assumptions provide alternative explanations for apparent recombinants. This is critical because even a few meioses incorrectly scored as recombinants substantially reduces the evidence for linkage [Ott, 1977]. Our strategy is sensible because the maximum LOD score is quite insensitive to misspecification of model parameters other than the degree of dominance [Clerget-Darpoux et al., 1986].

\section{RESULTS}

A genome scan was initially completed with 56 individuals from seven families with two or more affected relatives. Denser mapping of regions on chromosomes 2,9 , and 16 was subsequently done with those subjects and ten additional subjects from the largest family (see Fig. 1). Altogether, 65 of the 66 genotyped individuals were directly interviewed. Of the 59 directly interviewed relatives, 25 (nine males and 16 females) had a lifetime diagnosis of definite OCD. Five affected relatives were siblings, four were parents, eight were second-degree relatives, and eight were more distant relatives. They ranged in age from 12 to 89 years $(43.5 \pm 20.9$ years, mean \pm SD). OCD onset age ranged from five to 24 years $(12.1 \pm 5.6$ years, mean $\pm \mathrm{SD})$. Two affected relatives had a history of chronic tics. The 29 unaffected relatives (19 males, 10 females) ranged in age from 12 to 80 years $(44.5 \pm 19.8$ years, mean $\pm S D)$. Three relatives (two males, one female) had a lifetime history of subthreshold OCD and were considered unknown. They ranged in age from 18 to 48 years $(36.4 \pm 16.4$ years, mean \pm SD). A 10-year-old girl with possible compulsions was also considered unknown. None of the relatives with an unaffected or unknown phenotype had a history of tics.

The results from the parametric and nonparametric analyses using LMS v. 1 are shown in Figure 2. The maximum multipoint LOD score under the dominant model was 2.25 on chromosome $9 \mathrm{p}$ at $9.9 \mathrm{cM}$, corresponding to D9S288. Three other regions had LOD scores $>1$ under the dominant model: 1.12 on chromosome $16 \mathrm{q}$ at $92 \mathrm{cM}$, between D16S515 and D16S516; 1.06 on chromosome $2 \mathrm{q}$ at $237.1 \mathrm{cM}$, corresponding to D2S396; and 1.05 on chromosome $19 \mathrm{q}$ at $94 \mathrm{cM}$, corresponding to D19S210. Under the recessive model, three regions showed peak multipoint LOD scores $>1$ : 1.40 on chromosome $6 \mathrm{p}$ at $5 \mathrm{cM}$, corresponding to D6S470; 1.33 on chromosome $17 \mathrm{q}$ at $123 \mathrm{cM}$, between D17S784 and D17S928; and 1.07 on chromosome 2q at $237.1 \mathrm{cM}$, corresponding to D2S396.

The maximum multipoint nonparametric LOD* score was 1.73 on chromosome $19 \mathrm{q}$ at $89 \mathrm{cM}$, between D19S418 and D19S210. Three other regions had nonparametric LOD* scores $>1$ : 1.25 on chromosome 16q at $80 \mathrm{cM}$, between D16S515 and D16S516; 1.15 on chromosome $21 \mathrm{q}$ at $21 \mathrm{cM}$, between $\mathrm{D} 21 \mathrm{~S} 1253$ and D21S1263; and 1.01 on chromosome $2 \mathrm{q}$ at $240 \mathrm{cM}$, between D2S396 and D2S206.

Figure 3 shows the results for the fine mapping markers and the flanking LMS v. 1 markers on chromosomes 2,9 , and 16 in the 56 original subjects plus the ten subjects added in family 1 . With fine mapping and the additional subjects, the peak multipoint LOD score on $9 \mathrm{p}$ with the dominant model decreased slightly to 1.97 at $9.9 \mathrm{cM}$, corresponding to D9S288. The nonparametric LOD* score on $16 q$ increased slightly to 1.36 at $90.1 \mathrm{cM}$, between D16S3049 and D16S516. However, the LOD score under the dominant model in that region decreased substantially to -0.09 . The nonparametric LOD* score on $2 \mathrm{q}$ decreased to 0.77 at $239.2 \mathrm{cM}$, corresponding to D2S172. The dominant and recessive LOD scores on $2 q$ decreased substantially to 0.27 and -1.62 , respectively, at $237.1 \mathrm{cM}$, corresponding to D2S396.

\section{DISCUSSION}

To our knowledge, this is the first genome-wide linkage analysis of OCD. Although significant evidence for linkage was not detected on any chromosome using the Lander and Kruglyak criteria [1995], our LOD scores in a region near the telomere on $9 p$ meet the criterion for suggestive linkage. Lander and Kruglyak [1995] found by simulation that a whole genome screen should detect, on average, one LOD score exceeding 1.9, their threshold for suggestive linkage. Although a region with suggestive linkage may represent a false positive finding, they suggested that such evidence is strong enough to merit testing in an additional sample.

It should be noted that the strongest evidence for linkage was obtained with a parametric linkage analysis using a dominant transmission model. Previous segregation analyses of OCD have provided evidence for a single major locus that may have a dominant transmission pattern [Nicolini et al., 1991; Cavallini et al., 1999; Nestadt et al., 2000b]. The results from our linkage analysis, as well as from previous segregation analyses, indicate that it may be important to consider both parametric and nonparametric analyses in future linkage studies of OCD.

The decline in the LOD score for chromosome 9 with the family 1 extension may have been due to an increase in genetic information and/or genetic heterogeneity. The parents of two children with clinical diagnoses of autistic disorder and pervasive developmental disorder were included in the extension, although the children themselves were below the lower age limit for the study. A possible relationship between OCD and autistic disorder was noted in a family study in which OCD was significantly more common in relatives of autistic probands compared to relatives of Down syndrome probands [Bolton et al., 1998].

A report of $9 p$ monosomy in a patient with Tourette disorder and OCD is consistent with our finding of suggestive linkage in that region, and provides further support for the hypothesis that a susceptibility locus may be expressed as either disorder [Taylor et al., 1991]. Our LOD score of 1.40 on $6 p$ using a recessive model with marker D6S470 overlaps with a reported association between Tourette disorder and $6 \mathrm{p}$ markers in an Afrikaner sample [Simonic et al., 1998]. Twin and family studies indicate that some forms of OCD may be genetically related to Tourette disorder [Price et al., 1985; Pauls and Leckman, 1986; Pauls et al., 1986, 1991]. Furthermore, the distinction between tic-related 
Chromosome 1

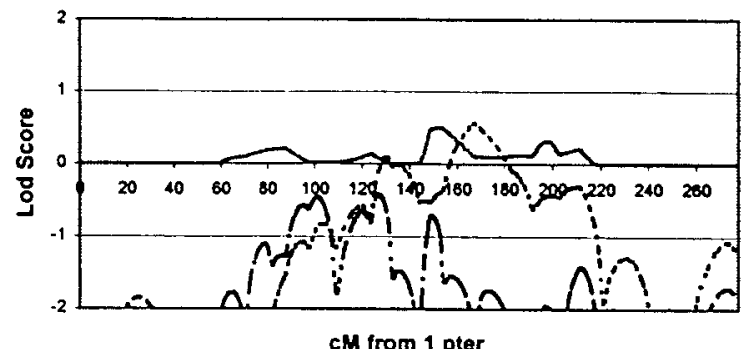

Chromosome 2

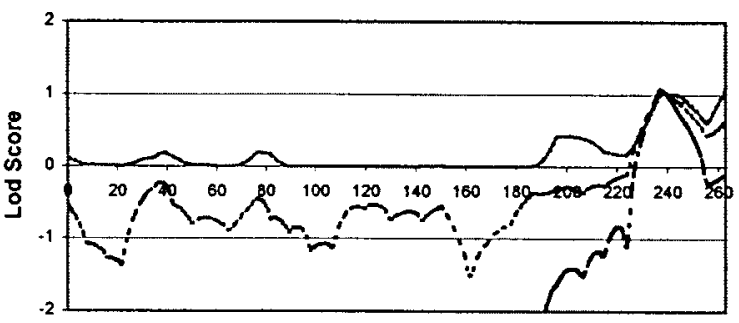

CM from 2 pter

Chromosome 3

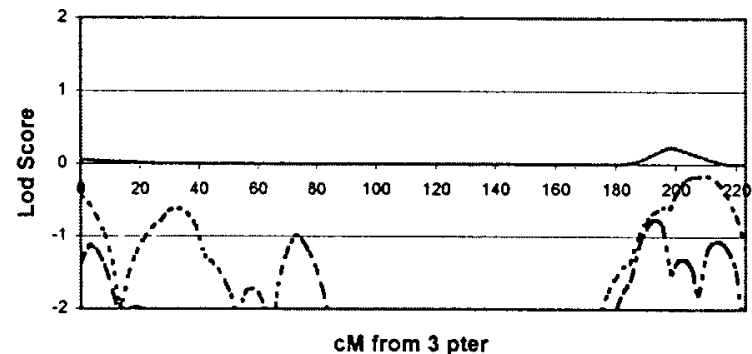

Chromosome 4

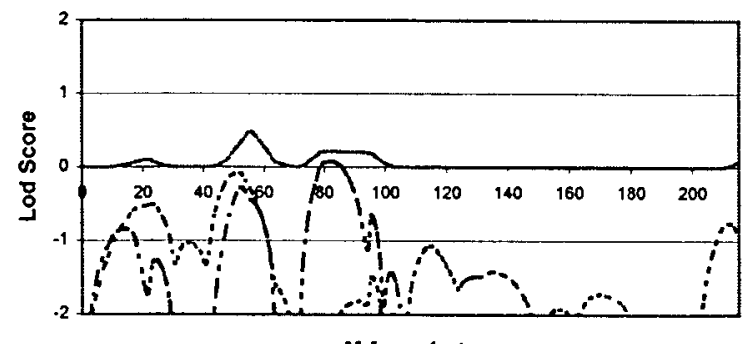

CM from 4 pter
Chromosome 5

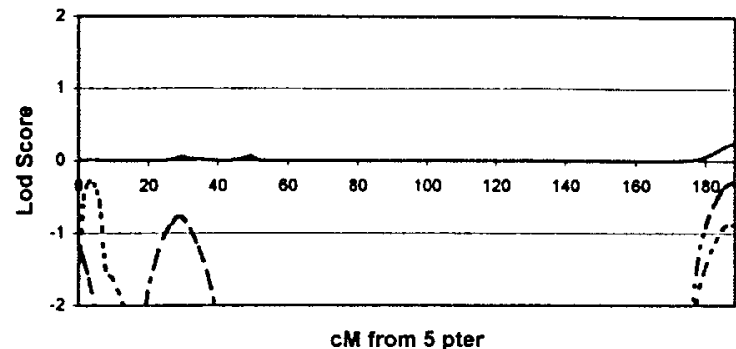

Chromosome 6

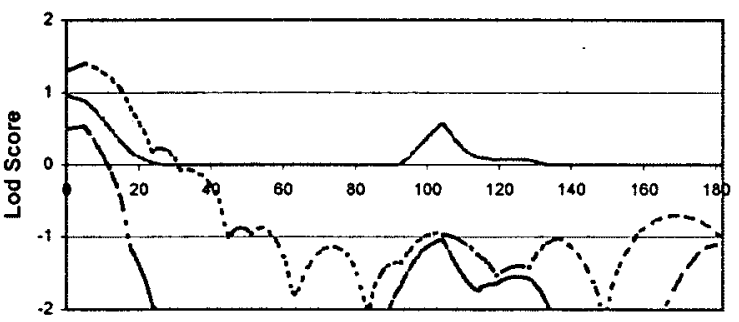

CM from 6 pter

Chromosome 7

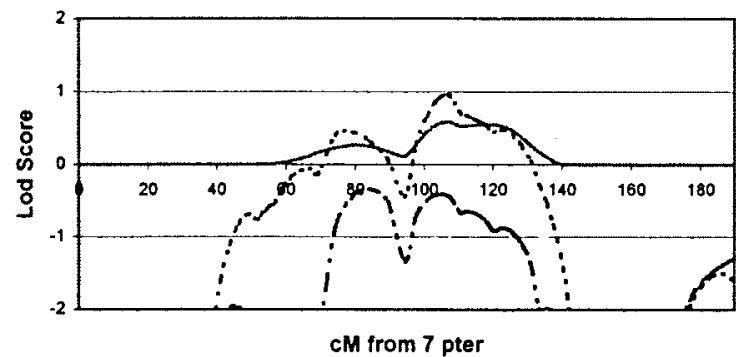

Chromosome 8

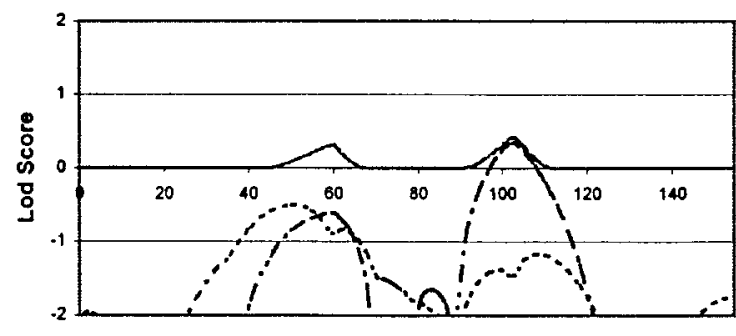

CM from 8 pter

Fig. 2. The results of a genome scan of early-onset OCD are presented with dominant, recessive, and GH+ LOD scores shown for each chromosome With the exception of chromosome 9, cM distances are given relative to the furthest pter marker on each chromosome in the ABI Linkage Mapping Set version 1, which is assigned a position of $0 \mathrm{cM}$. For chromosome $9, \mathrm{cM}$ distances are given relative to the furthest pter marker used for fine mapping so that the $\mathrm{y}$ axis begins at $9.9 \mathrm{cM}$. 
Chromosome 9

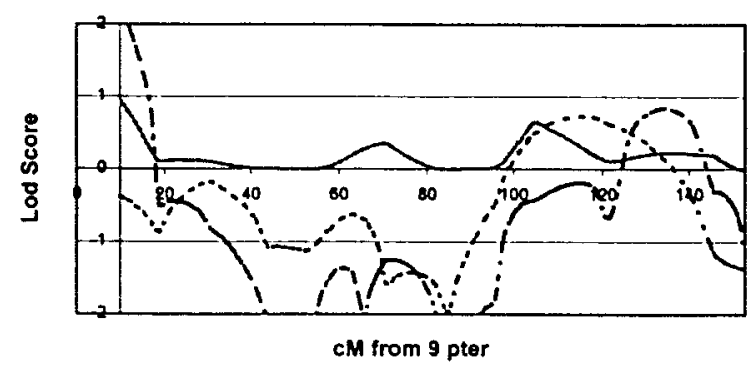

Chromosome 10

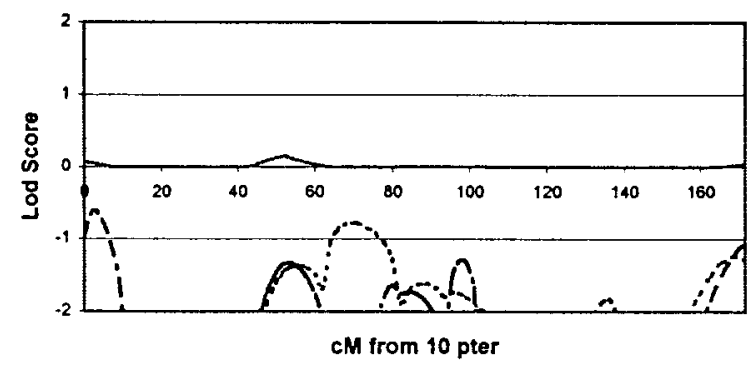

Chromosome 11

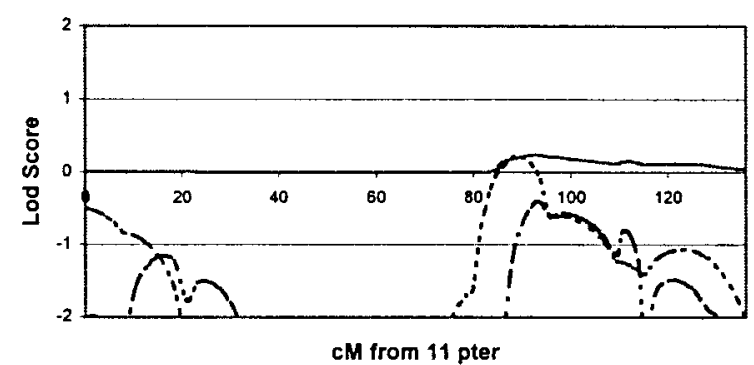

Chromosome 12

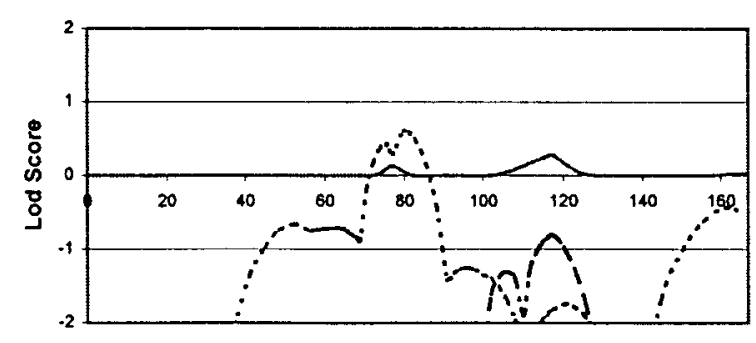

cM from 12 pter
Chromosome 13

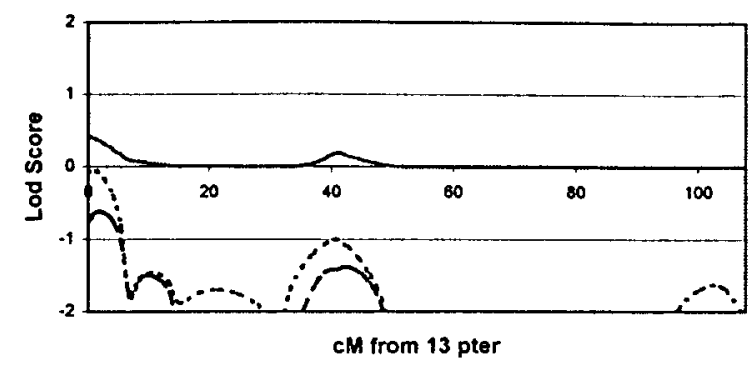

Chromosome 14

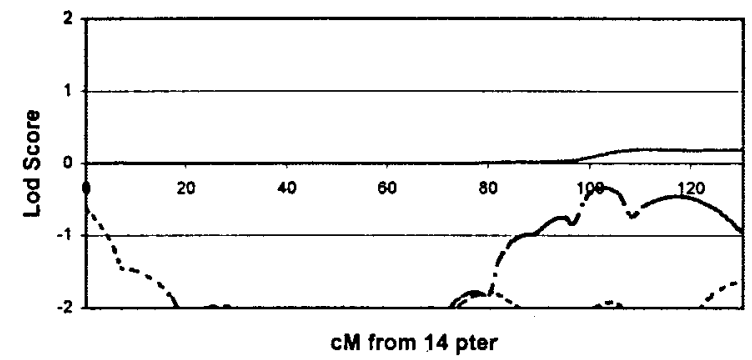

Chromosome 15

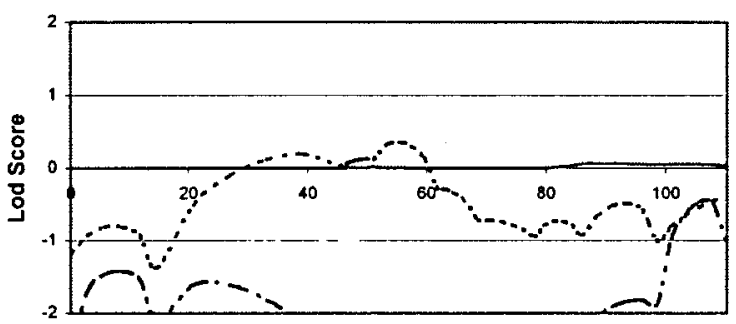

cM from 15 pter

Chromosome 16

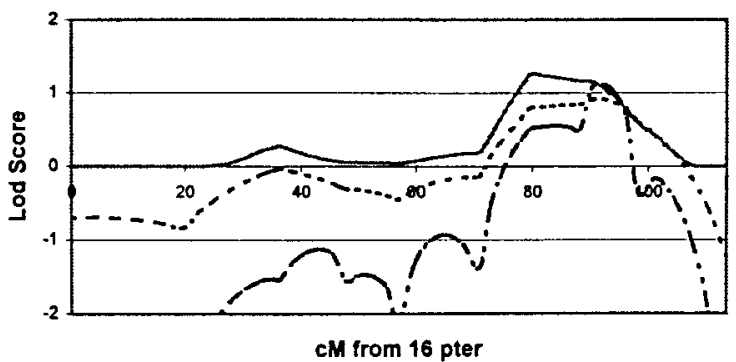

Fig. 2. (Continued) 
Chromosome 17

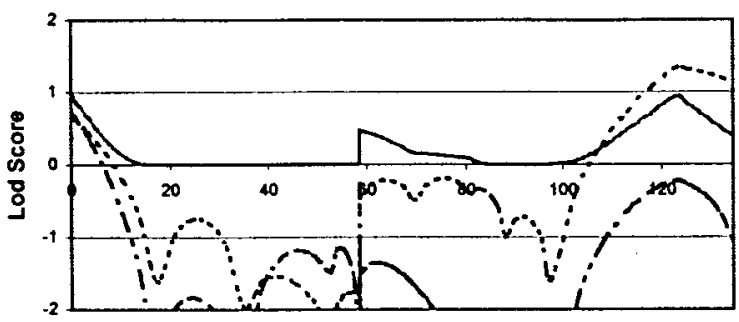

cM from 17 pter

Chromosome 18

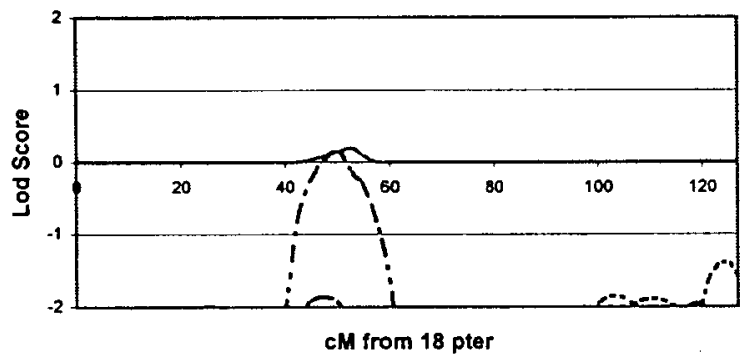

Chromosome 19

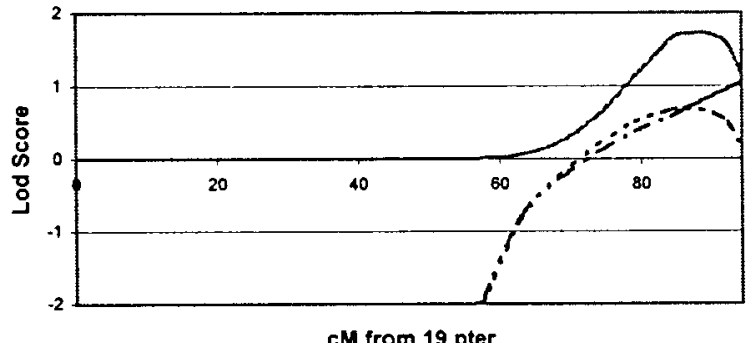

Chromosome 20

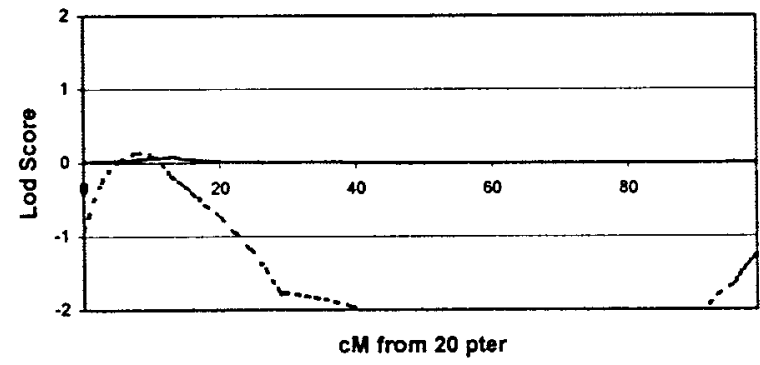

Chromosome 21

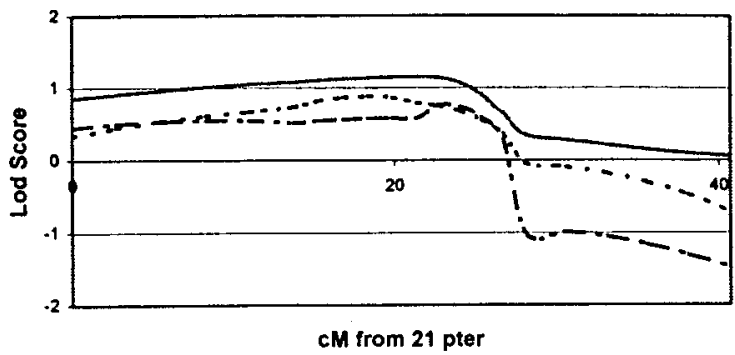

Chromosome 22

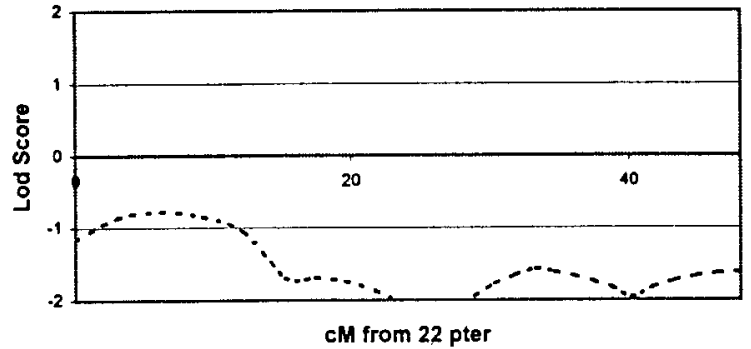

Chromosome $X$

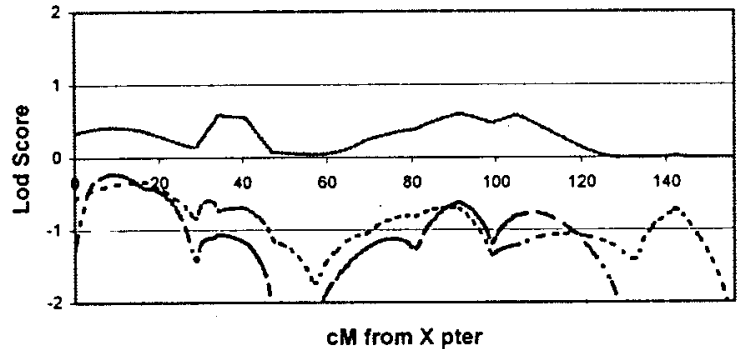

Dominant

Fig. 2. (Continued) 
a

Chromosome 2

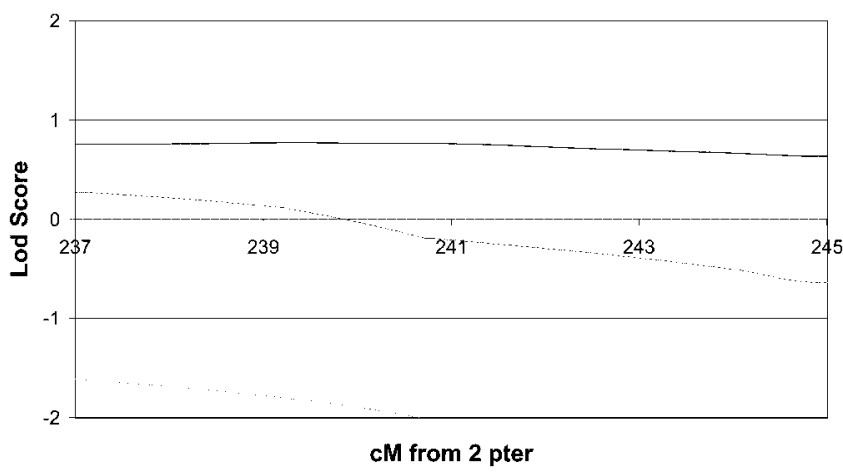

b

Chromosome 9

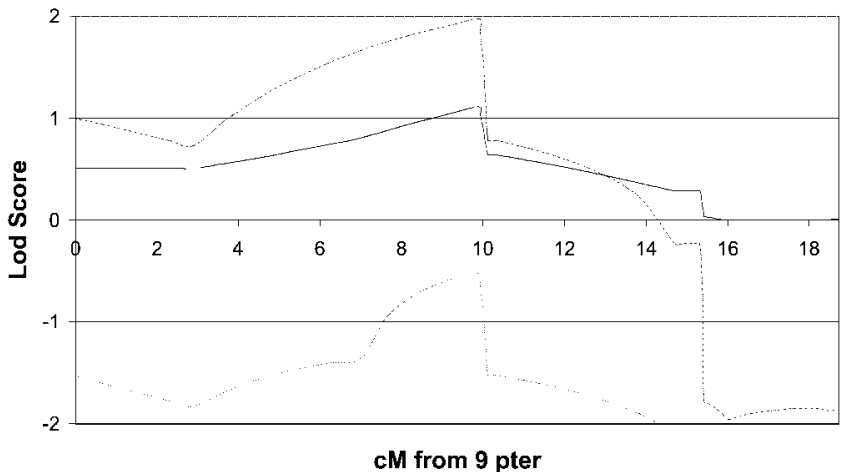

C

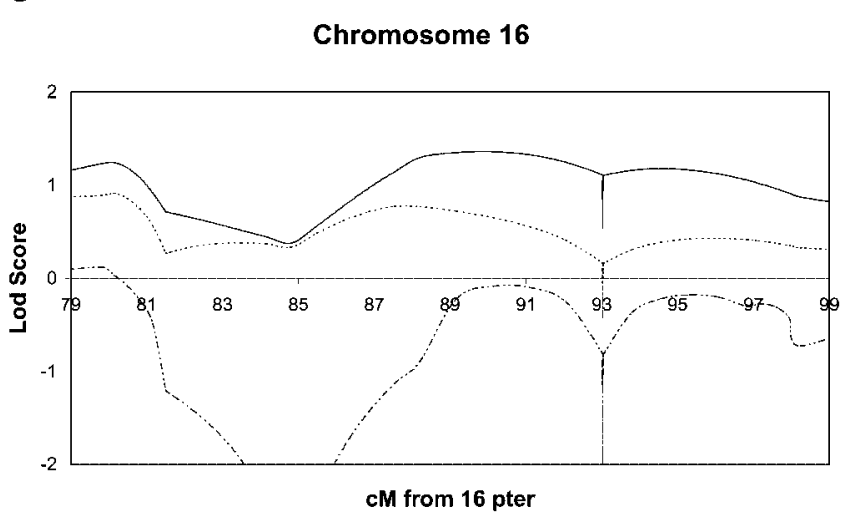

Fig. 3. The results from fine mapping are presented for chromosomes 2 , 9 , and 16 with dominant, recessive, and GH+ LOD scores shown for each. The cM distances presented here conform to those presented for the entire chromosomes. The LOD score lines are as follows: dominant (...................), recessive (..........), and GH+ LOD (-

and non-tic-related OCD has received support from a variety of studies [Hanna et al., 1991; Leonard et al., 1992; McDougle et al., 1994; Leckman et al., 1995; Pauls et al., 1995]. Tic-related OCD occurs more often in males than in females, and has an earlier age at onset than does non-tic-related OCD [Leonard et al., 1992; Leckman et al., 1995]. Hence, in families ascer- tained through pediatric OCD probands, the rate of tic-related-OCD may be increased.

A recent study of one large French Canadian family found significant linkage for Tourette disorder to $11 \mathrm{q}$ [Merette et al., 2000]. That region was also implicated by the association study of Tourette disorder in an Afrikaner population [Simonic et al., 1998]. A genome screen of sib pairs affected by Tourette disorder found suggestive evidence for linkage on $4 q$ and $8 p$ [Tourette Syndrome Association International Consortium for Genetics, 1999]. In contrast, a genome scan of several families with Tourette disorder found no significant or suggestive evidence for linkage [Barr et al., 1999]. In our linkage study of early-onset OCD, we found no evidence for linkage to chromosomes 4 , 8, or 11 . The molecular genetic relationship between OCD and Tourette disorder may be resolved with further linkage and family-based association studies.

Only one region provided suggestive evidence for linkage in our study. However, several other regions had some evidence for linkage, including $2 q, 6 p, 16 q$, $17 q$, and 19q. The LOD score of 1.33 on $17 q$ with a recessive model did not include the region containing the serotonin transporter gene, which has been implicated in family-based and case-control association studies of OCD [McDougle et al., 1998; Bengel et al., 1999]. Those regions with some evidence of linkage may prove interesting if they converge with findings in subsequent linkage studies. If one of those regions represents an actual weak linkage, that may be consistent with genetic heterogeneity or oligogenic inheritance. Conversely, each of those findings could represent a false positive finding.

Our genome scan of early-onset OCD did not include probands with neuropsychiatric symptoms related to streptococcal infection. It has been proposed that pediatric autoimmune neuropsychiatric disorders associated with streptococcal infection (PANDAS) account for a substantial minority of cases with early-onset OCD or Tourette disorder [Swedo et al., 1998]. The human leukocyte antigen (HLA) region on chromosome 6 is associated with a number of autoimmune disorders [Friday et al., 1999; McCurdy, 1999; Barbesino and Chiovato, 2000; Gough, 2000]. Although we found a mildly suggestive LOD score of 1.40 under the recessive model at D6S470 on $6 \mathrm{p}$, that marker is $26 \mathrm{cM}$ distal to the HLA region (closer to pter).

Based on linkage results in regions containing functional candidate genes, we sequenced the coding regions of two genes. This effort was motivated in part by an initial nonparametric analysis in which the genotypes of all affected individuals in a pedigree were examined simultaneously (data not shown), in contrast to our current analysis in which pairs of individuals are examined. As noted previously, examining all individuals simultaneously is more likely to produce false positive findings in a small sample [Kong and Cox, 1997]. We have reported the lack of coding region mutations leading to amino acid changes in both the SLC1A1/EAAC1 glutamate transporter gene on chromosome 9 [Veenstra-VanderWeele et al., 2001] and the $H T R 2 B$ serotonin receptor gene on chromosome 2 
[Kim et al., 2000]. It is still possible, nonetheless, that mutations in the regulatory regions for either of those genes could contribute to early-onset OCD.

The results from our preliminary linkage study of early-onset OCD should be interpreted with utmost caution. The power of the genome scan was limited by the small sample of 56 individuals so that only loci of very large effect may have been detectable. That is a major limitation of the study. The inclusion of four families in which five individuals had chronic tics in addition to OCD possibly increased the genetic heterogeneity of the sample. The parametric analysis using a dominant model that yielded a suggestive linkage finding on $9 p$ required generation of hypothetical gene frequency and penetrance values that cannot be empirically derived. Different penetrance functions may be considered for males and females based upon recent segregation analyses [Cavallini et al., 1999; Nestadt et al., 2001]. Furthermore, the results from a parametric linkage analysis in a small sample of extended families can be sensitive to diagnostic changes in a few critical individuals [Hodge and Greenberg, 1992]. If there is a susceptibility locus for early-onset OCD on $9 \mathrm{p}$, a larger sample will be required to produce significant evidence for linkage.

Because of the small sample size, we used only a narrow affection model (i.e., definite OCD) in our linkage analyses. However, it is possible that susceptibility loci involved in OCD may not be specific to the disorder. That is, one or more loci may also increase the risk for Tourette disorder [Price et al., 1985; Pauls and Leckman, 1986; Pauls et al., 1986] or anxiety disorders other than OCD [Torgersen, 1983; Andrews et al., 1990a, 1990b]. Given the problems associated with multiple testing, it seems reasonable in studies with small samples to expand the phenotype only after linkage is clearly established with a narrow affection model. Genome scans with much larger samples may be needed to establish significant evidence for linkage and to assess affection models for OCD.

\section{ACKNOWLEDGMENTS}

The authors thank Diane Q. Koram, MSW, Kristin R. Chadha, MSW, Katherine T. Gold, MSW, and Aileen H. Prout, MSW for their careful interviewing and commitment to the study. The authors thank Shuya Yan and Shanshan Zhang for expert technical assistance. The authors are especially grateful to the families who participated in the study. This work was supported, in part, by NIH K02 MH01389 (E.H.C.), NIH K20 MH01065 (G.L.H.), NIH R01 MH58376 (G.L.H.), the Jean Young and Walden W. Shaw Foundation (B.L.L.), the Harris Foundation (B.L.L.), the Brain Research Foundation (E.H.C.), University of Chicago, and the Obsessive Compulsive Foundation (E.H.C., G.L.H.).

\section{REFERENCES}

Alsobrook JP, Leckman JF, Goodman WK, Rasmussen SA, Pauls DL. 1999 Segregation analysis of obsessive-compulsive disorder using symptombased factor scores. Am J Med Genet 88:669-675.
American Psychiatric Association Committee on Nomenclature and Statistics. 1987. Diagnostic and statistical manual of mental disorders. 3rd ed. revised. Washington, DC: American Psychiatric Association. p 245.

American Psychiatric Association Committee on Nomenclature and Statistics. 1994. Diagnostic and statistical manual of mental disorders. 4th ed. p 420.

Andrews G, Stewart G, Allen R, Henderson AS. 1990a. The genetics of six neurotic disorders: a twin study. J Affect Disord 19:23-29.

Andrews G, Stewart G, Morris-Yates A, Holt P, Henderson S. 1990b. Evidence for a general neurotic syndrome. Br J Psychiatry 157:6-12.

Barbesino G, Chiovato L. 2000. The genetics of Hashimoto's disease. Endocrinol Metab Clin North Am 29:357-374.

Barr CL, Wigg KG, Pakstis AJ, Kurlan R, Pauls D, Kidd KK, Tsui LC, Sandor P. 1999. Genome scan for linkage to Gilles de la Tourette syndrome. Am J Med Genet 88:437-445.

Bengel D, Greenberg BD, Cora-Lacatelli G, Altemus M, Heils A, Li Q, Murphy DL. 1999. Association of the serotonin transporter promoter regulatory region polymorphism and obsessive-compulsive disorder. Mol Psychiatry 4:463-466.

Bolton PF, Pickles A, Murphy M, Rutter M. 1998. Autism, affective and other psychiatric disorders: patterns of familial aggregation. Psychol Med 28:385-395

Burke KC, Burke JD Jr, Regier DA, Rae DS. 1990. Age at onset of selected mental disorders in five community populations. Arch Gen Psychiatry 47:511-518.

Carey G, Gottesman II. 1981. Twin and family studies of anxiety, phobic and obsessive disorders. In: Klein DF, Rabkin J, editors. Anxiety: new research and changing concepts. New York: Raven Press. p 117-136.

Cavallini MC, Pasquale L, Bellodi L, Smeraldi E. 1999. Complex segregation analysis for obsessive compulsive disorder and related disorders. Am J Med Genet 88:38-43.

Clerget-Darpoux F, Bonaiti-Pellie C, Hochez J. 1986. Effects of misspecifying genetic parameters in lod score analysis. Biometrics 42:393-399.

Clifford CA, Murray RM, Fulker DW. 1984. Genetic and environmental influences on obsessional traits and symptoms. Psychol Med 14:791800 .

Douglass HM, Moffitt TE, Dar R, McGee R, Silva P. 1995. Obsessivecompulsive disorder in a birth cohort of 18-year-olds: prevalence and predictors. J Am Acad Child Adolesc Psychiatry 34:1424-1431.

Flament MF, Whitaker A, Rapoport JL, Davies M, Berg CZ, Kalikow K, Sceery W, Shaffer D. 1988. Obsessive compulsive disorder in adolescence: an epidemiological study. J Am Acad Child Adolesc Psychiatry 27:764-771.

Friday RP, Trucco M, Pietropaolo M. 1999. Genetics of Type 1 diabetes mellitus. Diabetes Nutr Metab 12:3-26.

Geller D, Biederman J, Jones J, Park K, Schwartz S, Shapiro S, Coffey B. 1998. Is juvenile obsessive-compulsive disorder a developmental subtype of the disorder? A review of the pediatric literature. J Am Acad Child Adolesc Psychiatry 37:420-427.

Goldstein RB, Wickramaratne PJ, Horwath E, Weissman MM. 1997. Familial aggregation and phenomenology of 'early'-onset (at or before age 20 years) panic disorder. Arch Gen Psychiatry 54:271-278.

Goodman W, Price L, Rasmussen S, Mazure C, Fleischmann R, Hill C, Heninger G, Charney D. 1989a. The Yale-Brown Obsessive Compulsive Scale: I. Development, use, and reliability. Arch Gen Psychiatry 46: 1006-1011.

Goodman W, Price L, Rasmussen S, Mazure C, Delgado P, Heninger G, Charney D. 1989b. Yale-Brown Obsessive Compulsive Scale: II. Validity. Arch Gen Psychiatry 46:1012-1016.

Gough SC. 2000. The genetics of Graves' disease. Endocrinol Metab Clin North Am 29:255-266.

Greenberg DA, Abreu P, Hodge SE. 1998. The power to detect linkage in complex disease by means of simple LOD-score analyses. Am J Hum Genet 63:870-879.

Hall JM, Lee MK, Newman B, Morrow JE, Anderson LA, Huey B, King MC. 1990. Linkage of early-onset familial breast cancer to chromosome 17q21. Science 250:1684-1689.

Hanna GL. 1995. Demographic and clinical features of obsessive-compulsive disorder in children and adolescents. J Am Acad Child Adolesc Psychiatry 34:19-27. 
Hanna GL, McCracken JT, Cantwell DP. 1991. Prolactin in childhood obsessive-compulsive disorder: clinical correlates and response to clomipramine. J Am Acad Child Adolesc Psychiatry 30:173-178.

Hanna GL, Himle JA, Curtis GC, Koram DQ, Veenstra-VanderWeele J, Leventhal BL, Cook EH. 1998. Serotonin transporter and seasonal variation in blood serotonin in families with obsessive-compulsive disorder. Neuropsychopharmacology 18:102-111.

Hettema JM, Neale MC, Kendler KS. 2001. A review and meta-analysis of the genetic epidemiology of anxiety disorders. Am J Psychiatry 158:1568-1578.

Hodge SE, Greenberg DA. 1992. Sensitivity of lod scores to changes in diagnostic status. Am J Hum Genet 50:1053-1066.

Inouye E. 1965. Similar and dissimilar manifestations of obsessive-compulsive neurosis in monozygotic twins. Am J Psychiatry 21:1171-1175.

Karno M, Golding JM, Sorenson SB, Burnam MA. 1988. The epidemiology of obsessive-compulsive disorder in five US communities. Arch Gen Psychiatry 45:1094-1099.

Kim S-J, Veenstra-VanderWeele J, Hanna GL, Gonen D, Leventhal BL, Cook EH. 2000. Mutation screening of human 5-HT2B receptor gene in early-onset obsessive-compulsive disorder. Molecular Cellular Probes 14:47-52.

Klein DN, Ouimette PC, Kelly HS, Ferro T, Riso LP. 1994. Test-retest reliability of team consensus best-estimate diagnoses of axis I and II disorders in a family study. Am J Psychiatry 151:1043-1047.

Kong A, Cox N. 1997. Allele-sharing models: LOD scores and accurate linkage tests. Am J Hum Genet 61:1179-1188.

Kruglyak L, Daly MJ, Reeve-Daly MP, Lander ES. 1996. Parametric and nonparametric linkage analysis: a unified multipoint approach. Am J Hum Genet 58:1347-1363.

Lander E, Kruglyak L. 1995. Genetic dissection of complex traits: guidelines for interpreting and reporting linkage results. Nat Genet 11:241-247.

Lander E, Schork N. 1994. Genetic dissection of complex traits. Science 265:2037-2048.

Last CG, Strauss CC. 1989. Obsessive-compulsive disorder in childhood. J Anxiety Disord 3:295-302.

Leckman JF, Sholomskas D, Thompson WD, Belanger A, Weissman MM. 1982. Best estimate of lifetime psychiatric diagnosis: a methodological study. Arch Gen Psychiatry 39:879-883.

Leckman JF, Grice DE, Barr LC, deVries ALC, Martin C, Cohen DJ, Goodman WK, Rasmussen SA. 1995. Tic-related vs. non-tic-related obsessive-compulsive disorder. Anxiety 1:208-215.

Lenane MC, Swedo SE, Leonard H, Pauls DL, Sceery W, Rapoport JL. 1990. Psychiatric disorders in first degree relatives of children and adolescents with obsessive compulsive disorder. J Am Acad Child Adolesc Psychiatry 29:407-412.

Leonard HL, Lenane MC, Swedo SE, Rettew DC, Gershon ES, Rapoport JL. 1992. Tics and Tourette's disorder: a 2- to 7-year follow-up of 54 obsessive-compulsive children. Am J Psychiatry 149:1244-1251.

Mannuzza S, Fyer AJ, Endicott J, Klein DF. 1985. Family Information Schedule and Criteria. New York: Anxiety Disorders Clinic, New York Psychiatric Institute.

McCurdy D. 1999. Genetic susceptibility to the connective tissue diseases. Curr Opin Rheumatol 11:399-407.

McDougle C, Goodman WK, Leckman JF, Lee NC, Heninger GR, Price LH. 1994. Haloperidol addition in fluvoxamine-refractory obsessivecompulsive disorder: a double blind placebo-controlled study in patients with and without tics. Arch Gen Psychiatry 51:302-308.

McDougle CJ, Epperson CN, Price LH, Gelernter J. 1998. Evidence for linkage disequilibrium between serotonin transporter protein gene (SLCD6A4) and obsessive compulsive disorder. Mol Psychiatry 3:270273

Merette C, Brassard A, Potvin A, Bouvier H, Rousseau F, Emond C, Bissonnette L, Roy MA, Maziade M, Ott J, Caron C. 2000. Significant linkage for Tourette syndrome in a large French Canadian family. Am J Hum Genet 67:1008-1013.

Nestadt G, Samuels J, Riddle M, Bienvenu OJ III, Liang KY, LaBuda M, Walkup J, Grados M, Hoehn-Saric R. 2000a. A family study of obsessive-compulsive disorder. Arch Gen Psychiatry 57:358-363.

Nestadt G, Lan T, Samuels J, Riddle M, Bienvenu O III, Liang K, HoehnSaric R, Cullen B, Grados M, Beaty T, Shugart Y. 2000b. Complex segregation analysis provides compelling evidence for a major gene underlying obsessive-compulsive disorder and for heterogeneity by sex. Am J Hum Genet 67:1611-1616.

Nicolini H, Hanna G, Baxter L, Schwartz J, Weissbecker K, Spence M. 1991. Segregation analysis of obsessive compulsive and associated disorders: preliminary results. Ursus Medicus 1:25-28.

Noshirvani HF, Kasvikis Y, Marks IM, Tsakiris F, Monteiro WO. 1991. Gender-divergent aetiological factors in obsessive-compulsive disorder. Br J Psychiatry 158:260-263.

Orvaschel H. 1987. Schedule for Affective Disorders and Schizophrenia for School-Aged Children-Epidemiologic Version: K-SADS-E. 4th ed. Philadelphia, PA: Medical College of Pennsylvania.

Ott J. 1977. Linkage analysis with misclassification at one locus. Clin Genet 12:119-124.

Pauls DL, Hurst CR. 1991a. Schedule for Tourette and Other Behavioral Syndromes (Adult on Child Form, Version C1). New Haven, CT: Child Study Center, Yale University School of Medicine.

Pauls DL, Hurst CR. 1991b. Schedule for Tourette and Other Behavioral Disorders (Adult Form, Version A1). New Haven, CT: Child Study Center, Yale University School of Medicine.

Pauls DL, Leckman JF. 1986. The inheritance of Gilles de la Tourette's syndrome and associated behaviors. N Engl J Med 315: 993-997.

Pauls DL, Towbin KE, Leckman JF, Zahner GEP, Cohen DJ. 1986. Gilles de la Tourette's syndrome and obsessive-compulsive disorder: evidence supporting a genetic relationship. Arch Gen Psychiatry 43:11801182.

Pauls DL, Raymond CL, Stevenson JM, Leckman JF. 1991. A family study of Gilles de la Tourette syndrome. Am J Hum Genet 48:154-163.

Pauls DL, Morton LA, Egeland JA. 1992. Risks of affective illness among first-degree relatives of bipolar I old-order Amish probands. Arch Gen Psychiatry 49:703-708.

Pauls DL, Alsobrook JP, Goodman W, Rasmussen S, Leckman JF. 1995. A family study of obsessive-compulsive disorder. Am J Psychiatry 152:76-84

Price RA, Kidd KK, Pauls DL, Cohen DJ, Leckman JF. 1985. A twin study of Tourette's syndrome. Arch Gen Psychiatry 42:815-820.

Pulver AE, Brown CH, Wolyniec P, McGrath J, Tam D, Adler L, Carpenter WT, Childs B. 1990. Schizophrenia: age at onset, gender and familia risk. Acta Psychiatr Scand 82:344-351.

Reinherz HZ, Giaconia RM, Lefkowitz ES, Pakiz B, Frost AK 1993. Prevalence of psychiatric disorders in a community population of older adolescents. J Am Acad Child Adolesc Psychiatry 32:369377 .

Simonic I, Gericke GS, Ott J, Weber JL. 1998. Identification of genetic markers associated with Gilles de la Tourette syndrome in an Afrikaner population. Am J Hum Genet 63:839-846.

Spitzer RL, Williams JB, Gibbon M, First MB. 1990. Structured Clinical Interview for DSM-III-R (SCID). Washington, DC: American Psychiatric Press.

Spitzer RL, Williams JB, Gibbon M, First MB. 1992. The Structured Clinical Interview for DSM-III-R (SCID). I: history, rationale, and description. Arch Gen Psychiatry 49:624-629.

Swedo SE, Leonard HL, Garvey M, Mittleman B, Allen AJ, Perlmutter S Lougee L, Dow S, Zamkoff J, Dubbert BK. 1998. Pediatric autoimmune neuropsychiatric disorders associated with streptococcal infections: clinical description of the first 50 cases. Am J Psychiatry 155:264271.

Taylor LD, Krizman DB, Jankovic J, Hayani A, Steuber PC, Greenberg F, Fenwick RG, Caskey CT. 1991. 9p monosomy in a patient with Gilles de la Tourette's syndrome. Neurology 41:1513-1515.

Thomsen PH. 1993. Obsessive-compulsive disorder in children and adolescents. Self-reported obsessive-compulsive behaviour in pupils in Denmark. Acta Psychiatr Scand 88:212-217.

Torgersen S. 1983. Genetic factors in anxiety disorders. Arch Gen Psychiatry 40:1085-1089

Tourette Syndrome Association International Consortium for Genetics. 1999. A complete genome screen in sib pairs affected by Gilles de la Tourette syndrome. Am J Hum Genet 65:1428-1436.

Valleni-Basile LA, Garrison CZ, Jackson KL, Waller JL, McKeown RE, Addy CL, Cuffe SP. 1994. Frequency of obsessive-compulsive disorder in a community sample of young adolescents. J Am Acad Child Adolesc Psychiatry 33:782-791. 
Van Broeckhoven C, Backhovens H, Cruts M, De Winter G, Bruyland M, Cras P, Martin JJ. 1992. Mapping of a gene predisposing to early-onse Alzheimer's disease to chromosome 14q24.3. Nat Genet 2:335-339.

Veenstra-VanderWeele J, Hanna GL, Leventhal BL, Cook EH. 1998 Coupling of optimized multiplex PCR and automated capillary electrophoresis for efficient genome-wide searches. Elsevier Trends Journals Technical Tips Online T01391.

Veenstra-VanderWeele J, Kim S-J, Gonen D, Hanna GL, Leventhal BL, Cook EH Jr. 2001. Genomic organization of the SLC1A1/EAAC1 gene and mutation screening in early-onset obsessive-compulsive disorder. Mol Psychiatry 6:160-167.

Weissman MM, Warner V, Wickramaratne P, Prusoff BA. 1988. Earlyonset major depression in parents and their children. J Affect Disord $15: 269-277$.
Weissman MM, Bland RC, Canino GJ, Greenwald S, Hwu HG, Lee CK, Newman SC, Oakley-Browne MA, Rubio-Stipec M, Wickramaratne PJ, Wittchen H-U, Yeh E-K. 1994. The cross national epidemiology of obsessive compulsive disorder. The Cross National Collaborative Group. J Clin Psychiatry 55 (Suppl):5-10.

Williams JB, Gibbon M, First MB, Spitzer RL, Davies M, Borus J, Howes MJ, Kane J, Pope HG Jr, Rounsaville B, Wittchen H-U. 1992. The Structured Clinical Interview for DSM-III-R (SCID). II. Multisite test-retest reliability. Arch Gen Psychiatry 49:630636.

Zohar AH, Ratzoni G, Pauls DL, Apter A, Bleich A, Kron S, Rappaport M, Weizman A, Cohen DJ. 1992. An epidemiological study of obsessivecompulsive disorder and related disorders in Israeli adolescents. J Am Acad Child Adolesc Psychiatry 31:1057-1061. 